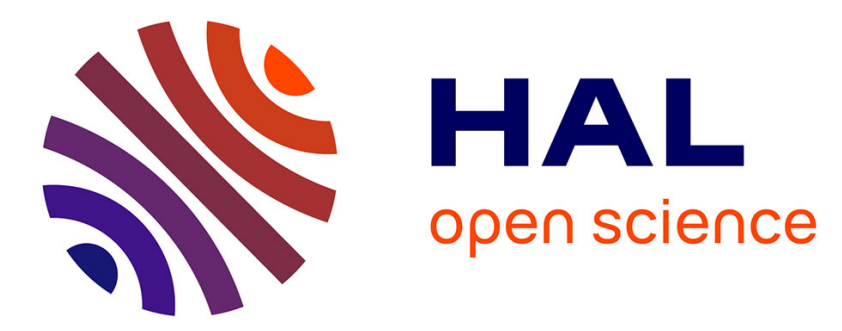

\title{
An electrochemical and structural investigation of silicon nanowires as negative electrode for Li-ion batteries
}

\author{
Barbara Laik, Diane Ung, Amael Caillard, Costel Sorin Cojocaru, Didier
}

Pribat, Jean Pierre Pereira-Ramos

\section{- To cite this version:}

Barbara Laik, Diane Ung, Amael Caillard, Costel Sorin Cojocaru, Didier Pribat, et al.. An electrochemical and structural investigation of silicon nanowires as negative electrode for Li-ion batteries. Journal of Solid State Electrochemistry, 2010, 14 (10), pp.1835-1839. 10.1007/s10008-010-1045-5 . hal-00794043

\section{HAL Id: hal-00794043 \\ https://hal.science/hal-00794043}

Submitted on 28 Feb 2013

HAL is a multi-disciplinary open access archive for the deposit and dissemination of scientific research documents, whether they are published or not. The documents may come from teaching and research institutions in France or abroad, or from public or private research centers.
L'archive ouverte pluridisciplinaire HAL, est destinée au dépôt et à la diffusion de documents scientifiques de niveau recherche, publiés ou non, émanant des établissements d'enseignement et de recherche français ou étrangers, des laboratoires publics ou privés. 


\title{
Journal of Solid State Electrochemistry \\ (2010) 14:1835-1839 \\ DOI 10.1007/s10008-010-1045-5
}

\section{An electrochemical and structural investigation of silicon nanowires as negative electrode for Li-ion batteries}

\author{
Barbara Laïk, Diane Ung, Amaël Caillard, Costel Sorin Cojocaru, Didier Pribat, Jean-Pierre Pereira-Ramos
}

B. Laïk $\left({ }^{\star}\right)$ : D. Ung $\cdot$ J.-P. Pereira-Ramos

Institut de Chimie et des Matériaux Paris Est, ICMPE/GESMAT, UMR 7182 CNRS-Université Paris XII, 2 rue Henri Dunant, 94320 Thiais, France

A. Caillard ${ }^{*}$ C. S Cojocaru ${ }^{*}$ D. Pribat

Laboratoire de Physique des Interfaces et Couches Minces, LPICM, UMR 7647 École Polytechnique-CNRS,

Route de Saclay,

91128 Palaiseau Cedex, France

\begin{abstract}
The electrochemical and structural responses of silicon nanowires deposited by chemical vapor deposition are investigated. Transmission electron microscopy and X- ray diffraction experiments show the electrochemical lithiation of SiNWs is not a quantitative process in good agreement with cycling experiments performed as a function of cycling limits. The SiNWs are not deeply lithiated as revealed by TEM micrographs. Our results suggest the existence of two well-defined lithiation steps,

first at $\sim 0.2 \mathrm{~V}$ into amorphous silicon and then into crystalline silicon at $\sim 0.1 \mathrm{~V}$. Cycling SiNWs above $100 \mathrm{mV}$ avoid the lithiation of c-Si which preserves the silicon 3-D architecture and results in good cycling performances. A stable capacity value of $\sim 500 \mathrm{mAh} \mathrm{g}^{-1}$ is achieved over at least 50 cycles.
\end{abstract}

Introduction

The increasingly demand on secondary batteries with higher specific energy densities requires new materials for both positive and negative electrodes. Concerning the negative, many researches are carried out in order to replace the actual electrode based on carbonaceous materials. Indeed, even if these materials are cheap and present interesting electrochemical properties, the maximal insertion of one lithium ion for six carbon atoms leads to a theoretical capacity limited to $372 \mathrm{mAh} \mathrm{g}^{-1}$. Because of its high theoretical specific capacity, silicon can appear as a good candidate (maximal insertion of $3.75 \mathrm{Li}$ ion for one Si atom at room temperature, which corresponds to a theoretical capacity of 3,580 $\mathrm{mAh} \mathrm{g}^{-1}$ ). However, the large volume expansion associated with lithium insertion, which can rise to more than $300 \%$, limits its ability to cycle with high efficiency. To solve the problem of cycle life, we propose to use a threedimensional architecture which leads on the one hand to a larger specific area and which allows on the other hand combining the accommodation of the large volume changes expected for lithium insertion in crystalline silicon with a continuous and efficient electrical contact between the $\mathrm{Si}$ particles. This architecture consists in a thin film based on $\mathrm{Si}$ nanowires (SiNWs) which are synthesized directly at the current collector surface by chemical vapor deposition (CVD) according to the vapor-liquid-solid (VLS) growth mechanism in $\mathrm{SiH} 4$ diluted in $\mathrm{H} 2$ in the temperature range of $520-580^{\circ} \mathrm{C}$.

To date, investigations devoted to such SiNWs as anodic materials for Li-ion batteries or microbatteries are very few [1-5] and indeed our first results are very promising [6]. The electrochemical behavior, studied in a two-electrode cell, has shown an attractive working potential window. Well-defined voltage plateaus are obtained and a low polarization leads to a narrow potential window between 0.1 and $0.45 \mathrm{~V}$ vs. $\mathrm{Li}^{+} / \mathrm{Li}$. Moreover, high storage capacities in the order of $1,500 \mathrm{mAh} \mathrm{g}^{-1}$ are achieved and are still available over more than 10 cycles [6].

From X-ray diffraction (XRD), transmission electron microscopy (TEM), and electrochemical experiments, the present study aims at providing additional piece of information on the reaction mechanism involved in the discharge/charge processes of SiNWs with the wish to 
achieve good cycle life without expecting the largest available capacities.

\section{Experimental}

SiNWs are synthesized by CVD according to the VLS growth mechanism which has been described elsewhere [6]. Among numerous experimental parameters such as the working pressure, the silane flow rate, the temperature, the substrate, the growth time, the temperature for the growth process seems to be one of the most important factors to control the formation of amorphous silicon. A decrease in the temperature will promote the deposition of amorphous silicon. In that case, scanning electron microscope (SEM) micrographs indicate the SiNWS are covered by aggregates or small particles of amorphous silicon (a-Si). However, a complete study to clearly understand and control the experimental factors allowing depositing a-Si has not been undertaken for the moment. The substrates used in this study were commercial stainless steel (316 L) or nickel foils of $50-\mu \mathrm{m}$ thickness.

Electrochemical studies were carried out in a two-electrode cell (Swagelok ${ }^{\circledR}$ type). This cell was prepared inside a dry box by placing a clean lithium metal disk ( $7 \mathrm{~mm}$ diameter), a glass fiber separator soaked with the electrolyte solution, a Celgard $₫$ disk and the cathode film $\left(0.28 \mathrm{~cm}^{2}\right)$ into a Teflon container with two stainless steel terminals. The electrolyte used was $1 \mathrm{~mol} \mathrm{~L}^{-1} \mathrm{LiClO}_{4}$, dried under vacuum at $180^{\circ} \mathrm{C}$ for $15 \mathrm{~h}$, dissolved in twice-distilled propylene carbonate obtained from Fluka. Galvanostatic measurements were made with a computer controlled 1470 A Solartron or MacPile (Biologic ${ }^{\circledR}$ ) potentiostat. A constant current density was used for charge/discharge experiments and a constant scan rate was used for voltametric measurements. XRD diffraction experiments were performed with a Inel Cps 300 diffractometer using the $\mathrm{Cu} \mathrm{Ka}$ radiation $(\lambda=1.54056 \AA)$. SEM and TEM images were respectively obtained with a LEO 1530 and an FEI Tecnai F20 ST microscopes.

\section{Results and discussion}

All the samples prepared according to the VLS method present the same aspect: a uniform carpet of nonpreferentially oriented nanowires covers the TiN-coated substrate. Figure 1 is a typical SEM image of thin SiNWs films. The analyzed sample has been grown during $15 \mathrm{~min}$ at $550^{\circ} \mathrm{C}$ and the mass deposit is in the order of $\sim 1 \mathrm{mg} \mathrm{cm}^{-2}$. The temperature, in the $520-580^{\circ} \mathrm{C}$ range, does not significantly affect the physical characteristics of SiNWs whereas the longer the growing process, the higher the silicon nanowires.

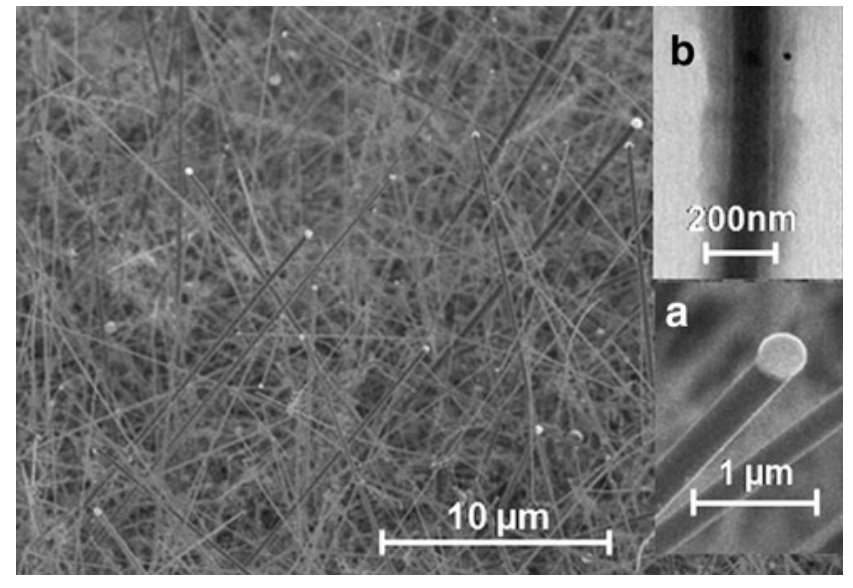

Fig. 1 SEM observations of SiNWs film obtained at $550^{\circ} \mathrm{C}$. a Zoom on a gold droplet in. b TEM observation of a silicon nanowire after a first reduction down to $20 \mathrm{mV}$

As it can be seen in the inset a, a small gold droplet, used as catalyst for the growth of Si wires, is still present at the top of each nanowire and controls the diameter size which is quite homogenous $(\sim 200 \mathrm{~nm})$. As lithium is known to electrochemically form alloys with gold at room temperature, we have previously evaluated the possible contribution of the Au droplets to the electrochemical discharge/charge process. The results, presented elsewhere [6], highlighted that the gold contribution cannot exceed at the best $\sim 10 \%$ of the capacity involved in the electrochemical process of the silicon nanowires and can then be neglected.

A TEM image of a fully lithiated silicon nanowire obtained by stopping the electrochemical cycle after a full discharge, i.e. at $0.02 \mathrm{~V}$, is presented in the inset b. Contrary to nanowires before cycling, two different areas can be distinguished: a core, in black, which is made of crystalline silicon and an outside sheath made of products originated from the decomposition of lithiated silicon compounds. This decomposition occurs during the sample transfer (a few seconds exposed to atmosphere) as well as under the electron beam [7].

The electrochemical behavior of SiNWs has been already partially investigated [6]. The major results are listed here. The curves obtained during the first reduction/ oxidation galvanostatic cycle versus lithium have mostly shown a single low voltage plateau located at around $0.1 \mathrm{~V}$ during lithiation. The corresponding derivate curve highlights a large peak usually ascribed to the formation of an amorphous lithiated silicon compound, identified as $\mathrm{Li}_{2.9} \mathrm{Si}$ [7] by valence electron energy-loss spectroscopy. During delithiation, a main voltage plateau is located at $0.45 \mathrm{~V}$ ascribed to the coming back to silicon. From the second cycle, the discharge profile is different: two reduction steps are observed at around $0.2 \mathrm{~V}$ and $0.1 \mathrm{~V}$. 
In addition to these obvious electrochemical processes, a close look at low potentials shows that another reaction takes place. This reaction, evidenced on the derivate curve, was correlated, as it will be established later, to the formation of the single available crystallized compound $\mathrm{Li}_{15} \mathrm{Si}_{4}$ at room temperature [8-10].

The new shape observed for the discharge/charge profiles from the second cycle is discussed in literature [11-13] and two different explanations can be found to justify the two electrochemical processes. The first one claims there are two successive single-phase regions. At high voltage ( $\sim 200 \mathrm{mV}$ ), an amorphous lithiated compound is in equilibrium with amorphous silicon (Eq. 1) whereas at lower voltage $(\sim 100 \mathrm{mV})$, a deeper lithiated alloy appears (Eq. 2) [11, 12].

$\mathrm{a}-\mathrm{Si}+\mathrm{xLi} \leftrightarrow \mathrm{a}-\mathrm{Li}_{\mathrm{x}} \mathrm{Si} \quad$ (probably a $-\mathrm{Li}_{7} \mathrm{Si}_{3}$

$\mathrm{a}-\mathrm{Li}_{\mathrm{x}} \mathrm{Si}+\mathrm{yLi} \leftrightarrow \mathrm{a}-\mathrm{Li}_{\text {xpy }} \mathrm{Si} \quad\left(\right.$ probably $\left.\mathrm{a}-\mathrm{Li}_{13} \mathrm{Si}_{4}\right)(2)$

More recently, another explanation has been proposed [13]: the two steps could correspond to the alloying process of lithium in two different kinds of silicon, namely amorphous silicon at around $200 \mathrm{mV}$ and crystalline silicon at around $100 \mathrm{mV}$. Such an explanation is consistent with other results obtained with thin films of amorphous silicon [14-16].

Results obtained with different samples grown under different experimental conditions tend to support the Cui's group explanation. Figure 2 illustrates the first alloying/

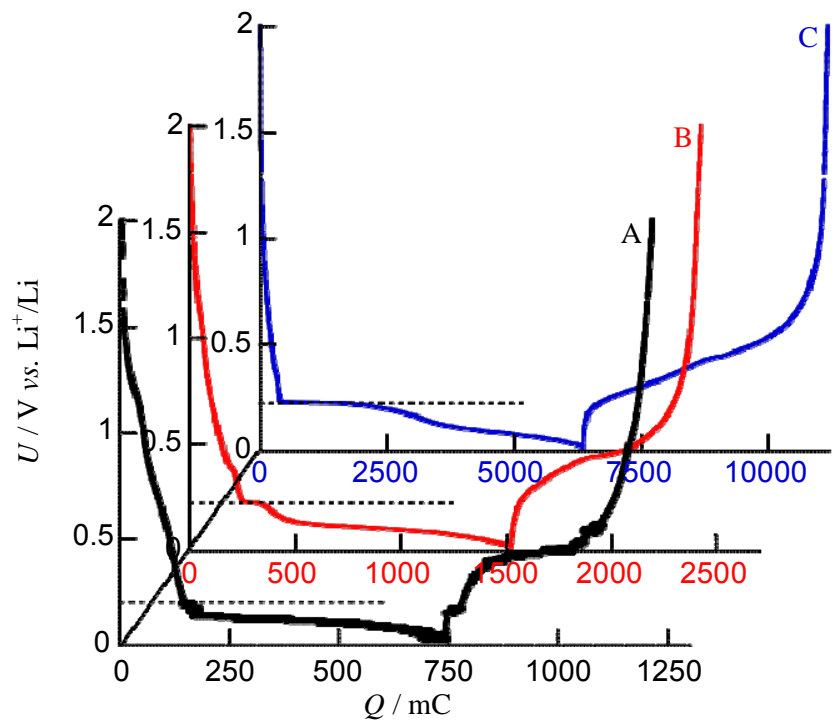

Fig. 2 First discharge-charge cycle (a $10 \mu \mathrm{A}$, b $20 \mu \mathrm{A}$, c $50 \mu \mathrm{A}$ ) for three SiNWs films obtained under different growing experimental conditions (a $525^{\circ} \mathrm{C}, 15 \mathrm{~min}$; b $540^{\circ} \mathrm{C}, 15 \mathrm{~min}$; c $540^{\circ} \mathrm{C}, 60 \mathrm{~min}$ ) dealloying cycle for three samples grown under different experimental conditions (temperature, deposition time). Depending on these growth conditions, the plateau observed at $0.2 \mathrm{~V}$ is longer or shorter. For sample A $\left(525^{\circ} \mathrm{C}, 15 \mathrm{~min}\right)$ reported as very well crystallized silicon [6], the $0.2 \mathrm{~V}$ step (highlighted by a dashed line) does not practically appears. A closer look at the micrograph of the sample before cycling (presented in the inset of the Fig. 8 in reference [6]) shows that some nanowires present some roughness of surface which could be ascribed to the presence of amorphous silicon.

For samples B and C (grown at $540^{\circ} \mathrm{C}$, respectively during 15 and $60 \mathrm{~min}$ ), the significant plateau at $0.2 \mathrm{~V}$ could correspond to larger amounts of a-Si.

Only a semi-quantitative investigation could elucidate the relation between the ratios of a-Si/c-Si amounts and $0.2 \mathrm{~V} / 0.1 \mathrm{~V}$ plateau lengths. This will be done in a further work since we know that modifying the SiNWs growth conditions enables to increase the amount of amorphous silicon at the surface of well crystallized silicon wires.

Further, we have examined the influence of the cycling limits on capacity and cycle life of SiNWs. Figure 3 reports the evolution of the capacity versus the cycle number for two samples grown at $540{ }^{\circ} \mathrm{C}$ during $60 \mathrm{~min}$. The first one is cycled between $3 \mathrm{~V}$ and $20 \mathrm{mV}$ (blue points). The cutoff voltage of $20 \mathrm{mV}$ is quite low to involve the crystallized silicon in the reduction processes. The second one is cycled between $3 \mathrm{~V}$ and $100 \mathrm{mV}$ (red points), hindering then the expected $\mathrm{Li}$ alloying in $\mathrm{c}-\mathrm{Si}$. Cycling over the whole potential range entails a rapid and continuous decrease of the capacity since $50 \%$ of the initial capacity is lost after 50 cycles. When the cycling window is reduced, the capacity

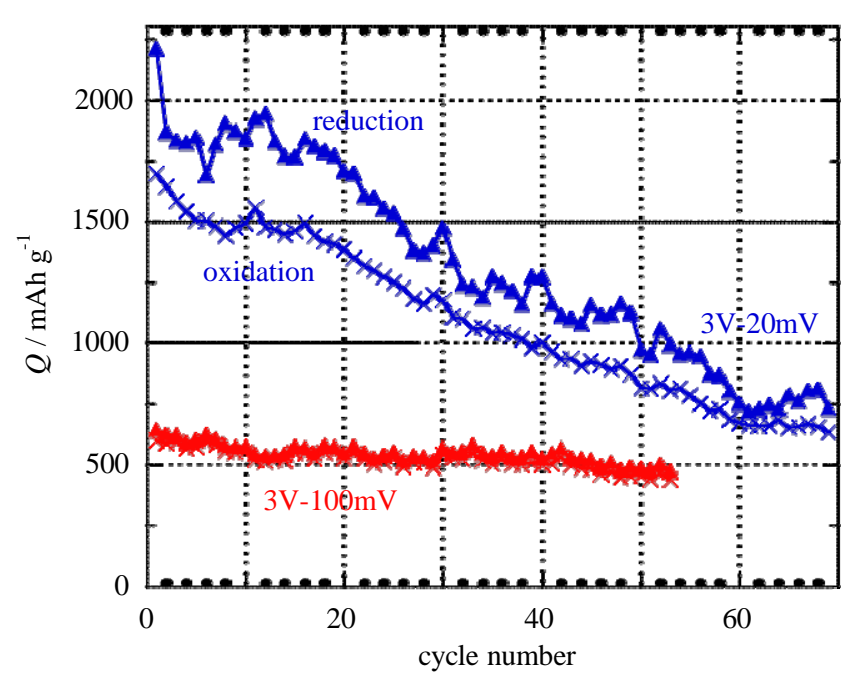

Fig. 3 Charge (filled triangle) and discharge (multiplication symbol) capacities versus cycle number for SiNWs films, grown at $540^{\circ} \mathrm{C}$ during $60 \mathrm{~min}$, under $70 \mu \mathrm{A} \mathrm{cm}{ }^{-2}$, with different low voltage cutoffs: $20 \mathrm{mV}$ (blue data) and $100 \mathrm{mV}$ (red data) 
is lower $\left(\sim 600 \mathrm{mAh} \mathrm{g}^{-1}\right)$ but still much higher than that of graphite. This capacity is stable, with $500 \mathrm{mAh} \mathrm{g}^{-1}$ over at least 50 cycles. Additional cycling experiments have been performed in order to avoid the $\mathrm{Li}_{15} \mathrm{Si}_{4}$ formation. Cycling with the restricted cutoff voltages $3 \mathrm{~V}-50 \mathrm{mV}$ and $3 \mathrm{~V}$ $80 \mathrm{mV}$, give similar results to those obtained with a lower potential limit of $20 \mathrm{mV}$, namely a fast capacity decline.

A first investigation of the rate capability for the SiNWs is illustrated in Fig. 4. The specific capacity decreases slightly from $1,200 \mathrm{mAh} \mathrm{g}^{-1}$ to about $900 \mathrm{mAh} \mathrm{g}^{-1}$ when the $\mathrm{C}$ rate changes from $\mathrm{C} / 100$ to $\mathrm{C} / 10$. A capacity of $600 \mathrm{mAh} \mathrm{g}^{-1}$ is still achieved at $\mathrm{C} / 4$ without damaging the active material since upon returning to cycling at $\mathrm{C} / 100$ rate, the cell recovers a high capacity close to $1,200 \mathrm{mAh} \mathrm{g}^{-1}$.

In the first papers devoted to the study of silicon as anode materials for Li-ion batteries, the formation of the crystallized phase $\mathrm{Li}_{15} \mathrm{Si}_{4}$ was thought to be responsible for the poor cyclability [8]. From the present cycling results reported here, it is suggested that the Li-alloying process into crystallized silicon is unfavorable to the cycle life. Indeed, from XRD experiments, the formation of the $\mathrm{c}-\mathrm{Li}_{15} \mathrm{Si}_{4}$ alloy is proved to take place only at very low potential. Figure 5 displays different X-ray patterns registered before cycling, when the SiNWs electrode is discharged to $0.11 \mathrm{~V}$ and $0.02 \mathrm{~V}$ and charged up to $3.00 \mathrm{~V}$ during the first cycle, and at the bottom of discharge $(0.02 \mathrm{~V})$ during the second cycle. Besides diffraction peaks characteristic to the nickel substrate ( $\mathbf{A}$ ), the expected diffraction lines for crystallized silicon are present $(*)$. These peaks are the more intense before cycling and then never disappear, which indicates that only a part of the initial amount of crystallized silicon participates to the electrochemical process. Moreover, they

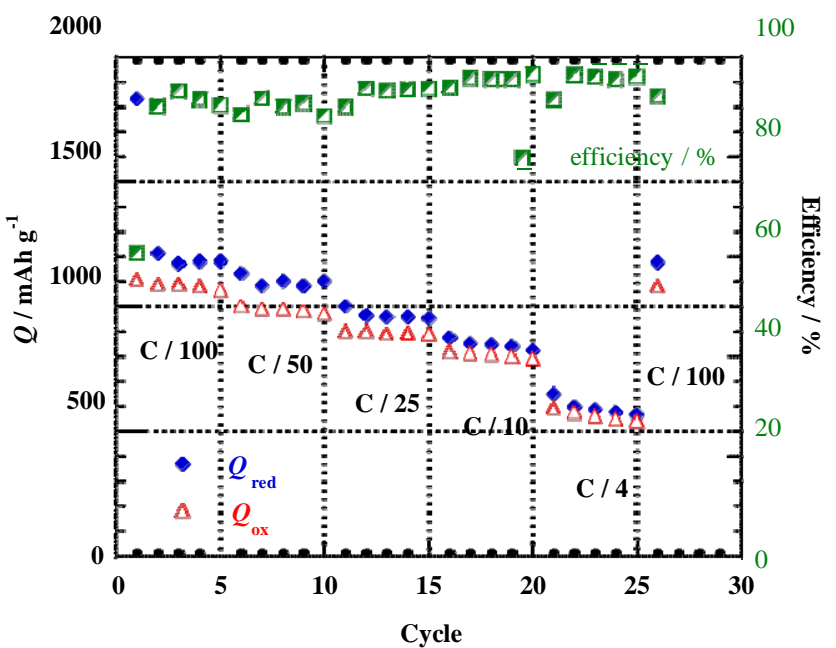

Fig. 4 Influence of the rate capability and coulombic efficiency as a function of the cycle number for SiNWs film grown at $540^{\circ} \mathrm{C}$ during $15 \mathrm{~min}$

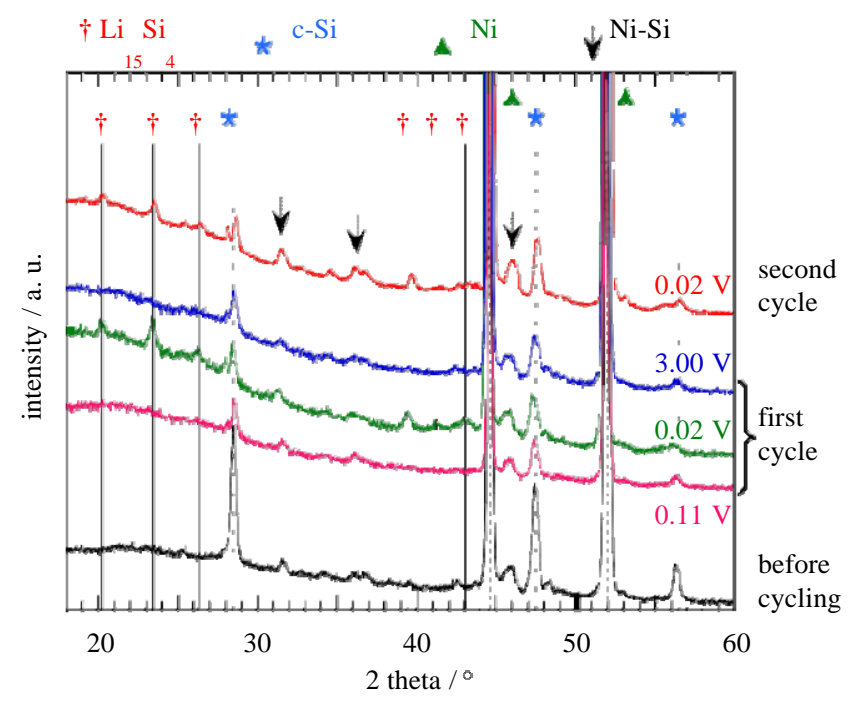

Fig. 5 XRD patterns of SiNWs films, grown at $540{ }^{\circ} \mathrm{C}$ during $15 \mathrm{~min}$, before electrochemical cycling, during the first cycle when material is discharged to $0.11 \mathrm{~V}$ and $0.02 \mathrm{~V}$ and charged up to $3.00 \mathrm{~V}$, and when fully discharged to $0.02 \mathrm{~V}$ during the second cycle $\left(70 \mu \mathrm{A} \mathrm{cm}{ }^{-2}\right)$

do not increase after a complete cycle suggesting that delithiation of $\mathrm{c}-\mathrm{Li}_{15} \mathrm{Si}_{4}$ leads to amorphous silicon and not to crystalline silicon phase. Considering the diffractogram at the mid-discharge of the first cycle, no new reflection showing formation of any crystalline phase appears. When potential reaches low values close to $20 \mathrm{mV}$, new peaks appear $(\dagger)$. They are characteristic of the crystalline phase $\mathrm{Li}_{15} \mathrm{Si}_{4}$ [8]. These peaks disappear during the reverse scan and reappear at the end of the following reductions. Additional peaks $(\downarrow)$, that do not change during cycling, can be seen. They correspond to nickel-silicon alloys, formed from the original substrate made of nickel. Cui and his group have already reported a similar phenomenon when stainless steel substrates are used for the SiNWs growth. Iron-silicon alloy forms at the interface between the current collector and the silicon wires since the temperature is elevated above $520^{\circ} \mathrm{C}$ during the synthesis [2]. According to their paper, Fe-Si alloy was not found to appreciably react with lithium identically to Ni-Si in our case. Nevertheless, it can be asked whether the presence of this alloy has an incidence on the achieved capacities as we observed that they tend to be higher when nickel-silicon alloys were identified in the sample insofar as this kind of alloy is known to be a very good electronic conductor $[17,18]$.

\section{Conclusion}

This work confirms SiNWs present an interesting behavior as negative electrode for rechargeable lithium micorobatteries: an attractive working potential window $\left(<0.5 \mathrm{~V}\right.$ vs. $\left.\mathrm{Li}^{+} / \mathrm{Li}\right)$ 
and a low polarization (very well-defined plateaus in reduction and in oxidation at close potentials). TEM, XRD, and galvanostatic data indicate that only a part of c-Si is involved. Our results are consistent with the two successive $\mathrm{Li}$ alloying reactions into amorphous $\mathrm{Si}$ at $\sim 0.2 \mathrm{~V}$ and then into crystalline $\mathrm{Si}$ at $\sim 0.1 \mathrm{~V}$. When the second system is involved in the cycling experiments, a drastic capacity decline occurs. A very high rechargeability is ensured with appropriate cycling limits corresponding to Li-alloying/dealloying reactions into/from amorphous $\mathrm{Si}$. As an example, a stable capacity of about $500 \mathrm{mAh} \mathrm{g}^{-1}$ can be then achieved over at least 50 cycles between $3 \mathrm{~V}$ and $0.1 \mathrm{~V}$.

Since we know that modifying the SiNWs growth conditions enables to increase the amount of amorphous silicon at the surface of well crystallized silicon wires, a semi-quantitative investigation is under progress in order to understand the relation between the ratios of a-Si/c-Si and electrochemical properties.

\section{References}

1. Peng K, Jie J, Zhang W, Lee ST (2008) Appl Phys Lett 93:033105-1-033105-3
2. Chan CK, Peng H, Liu G, McIlwrath K, Zhang XF, Huggins RA, Cui Y (2008) Nat Nanotechnol 3:31-35

3. Chan CK, Ruffo R, Hong SS, Cui Y (2009) J Power Sources 189:1132-1140

4. Ruffo R, Hong SS, Chan CK, Huggins RA, Cui Y (2009) J Phys Chem C 113:11390-11398

5. Chan CK, Ruffo R, Hong SS, Huggins RA, Cui Y (2009) J Power Sources 189:34-39

6. Laik B, Eude L, Pereira-Ramos JP, Cojocaru CS, Pribat D, Rouvière E (2008) Electrochim Acta 53:5528-5532

7. Danet J, Brousse T, Rasim K, Guyomard D, Moreau P (2010) Phys Chem Chem Phys 12:220-226

8. Obrovac MN, Christensen L (2004) Electrochem Solid-State Lett 7:A93-A96

9. Hatchard TD, Dahn JR (2004) J Electrochem Soc 151:A838A842

10. Li J, Dahn JR (2007) J Electrochem Soc 154:A156-A161

11. Obrovac MN, Krause LJ (2007) J Electrochem Soc 154:A103A108

12. Ding N, Xu J, Yao YX, Wegner G, Fang X, Chen CH, Lieberwirth I (2009) Solid State Ion 180:222-225

13. Cui LF, Ruffo R, Chan CK, Peng H, Cui Y (2009) Nano Lett 9:491-495

14. Bourderau S, Brousse T, Schleich DM (1999) J Power Sources 81-82:233-236

15. Baranchugov V, Markevich E, Polak E, Salitra G, Aurbach D (2007) Electrochem Commun 9:796-800

16. Kulova TL (2008) Russ J Electrochem 44:525-529

17. Aime D (2007) Ph.D thesis, INSA, Lyon, France

18. Imbert B (2009) Ph.D thesis, INP Grenoble, France 